\title{
Bronchoalveolar lavage in patients with mild and severe rheumatoid lung disease
}

\author{
D M Gilligan, C M O'Connor, K Ward, D Moloney, B Bresnihan, M X FitzGerald
}

\begin{abstract}
The reported prevalence of interstitial lung disease in patients with rheumatoid arthritis has varied from $10 \%$ to $50 \%$, yet less than $5 \%$ of patients with arthritis develop severe fibrosing interstitial lung disease. This suggests that subclinical disease may not always presage progressive disease. Bronchoalveolar lavage fluid from patients with rheumatoid arthritis and either clinically evident interstitial lung disease or subclinical disease was examined for the presence of factors with a putative role in the development of interstitial fibrosis. Patients with subclinical disease were identified by prospective radiographic and lung function screening of 93 patients with rheumatoid arthritis. Fourteen patients were identified in this: manner and an association between subclinical disease and smoking history was noted. Eleven patients with established interstitial lung disease had increased neutrophils $(p<0.05)$, collagenase, and type III procollagen $N$ terminal peptide levels $(p<0.01)$ in the bronchoalveolar lavage fluid. Preliminary characterisation of the bronchoalveolar lavage collagenase suggested that it originated from neutrophils. Ten patients with subclinical interstitial lung disease underwent bronchoalveolar lavage. Of these, one had increased neutrophils and two had increased collagenase concentrations-abnormalities associated with advanced interstitial lung disease and a poor prognosis. These results suggest that in arthritis patients with evidence of subclinical pulmonary interstitial disease bronchoalveolar lavage might be useful in identifying those who may require careful monitoring in the hope that early treatment will prevent severe fibrosis.
\end{abstract}

Dublin

D M Gilligan

$\mathrm{K}$ Ward

B Bresnihan

M X FitzGerald

Department of

Medicine, University

College, Dublin,

Ireland

C M O'Connor

KWard

D Moloney

M X FitzGerald

Address for reprint requests: Dr C M O'Connor, Department of Medicine, University College, Dublin, Belfield, Dublin 4, Ireland.

Accepted 3 April 1990 arthritis for interstitial lung disease shows prevalences of $10-50 \%{ }^{3-6}$ This wide variation probably reflects differences in the methods used to assess lung disease and in the popula-

Interstitial lung disease is the most compros tion of rheumatoid arthritis. ${ }^{1}$ Patients may develop a severe, progressive fibrosing alveolitis which is clinically and histologically similar to cryptogenic fibrosing alveolitis. ${ }^{2}$ tions of patients examined. Whichever value is accepted, the proportion of patients with rheumatoid arthritis who develop severe fibrosing alveolitis is clearly lower. Patients identified by screening are usually symptomless and have mild radiographic or pulmonary function abnormalities. ${ }^{346}$ It would be of great clinical benefit to identify patients in whom mild pulmonary abnormality is likely to progress to more advanced disease.

Bronchoalveolar lavage allows detection of inflammation in the lower respiratory tract and may provide prognostic information in cryptogenic fibrosing alveolitis. ${ }^{78}$ Bronchoalveolar lavage studies in patients with rheumatoid arthritis and established interstitial lung disease have shown abnormalities similar to those of cryptogenic fibrosing alveolitis. ${ }^{910}$ Bronchoalveolar lavage in patients with rheumatoid arthritis but little or no lung disease showed lymphocytic alveolitis in some patients, which it was suggested might proceed to more severe lung disease. ${ }^{911}$ Other studies, however, suggest that increased lymphocytes in bronchoalveolar lavage fluid are associated with a good pulmonary prognosis in patients with collagen vascular disorders $^{12}$ and cryptogenic fibrosing alveolitis. ${ }^{7}$ Assessment of lavage fluid from patients with rheumatoid arthritis for markers implicated in the development of severe fibrosing disease may help to identify patients likely to develop serious pulmonary complications. In this study the levels of several such markersneutrophils, collagenase, type III procollagen peptide, and fibronectin ${ }^{73-15}$-were determined in lavage fluid from patients with rheumatoid arthritis with and without established interstitial lung disease.

\section{Methods}

PATIENTS

We prospectively screened 93 patients with rheumatoid arthritis as defined by the American Rheumatism Association ${ }^{16}$ for subclinical pulmonary abnormalities. We selected them from consecutive patients attending a rheumatology outpatient clinic or admitted to an inpatient rehabilitation unit during October 1987-May 1988. Patients were excluded if they were under 20 or over 65 years, if there was any doubt about the diagnosis of rheumatoid arthritis, or if they were severely debilitated-that is, grade 4 on the American Rheumatism Association classification. ${ }^{16}$ Posteroanterior and lateral chest radiographs were obtained. Interstitial changes were classified according to 
the International Labour Office (ILO) classification. ${ }^{17}$ Spirometry was performed with either a bellows vitalograph or a portable electronic vitalograph. Values were expressed as a percentage of the normal for sex, age, and height. ${ }^{18}$ This system of screening was chosen because it could be performed during a follow up assessment in a rheumatology clinic. A patient was considered to show evidence of interstitial lung disease if two observers agreed that there was an interstitial infiltrate on the chest radiograph or if the forced vital capacity (FVC) was under $80 \%$ while the $\mathrm{FEV}_{1} / \mathrm{FVC}$ ratio was normal (that is, over $70 \%$ ).

For each patient we obtained a detailed history of the diagnosis, course, and treatment of their rheumatoid arthritis and current respiratory symptoms and also a smoking history. A physical examination was performed to determine the extent of joint lesions and the presence or absence of subcutaneous nodules, finger clubbing, and chest signs.

Ten patients with evidence of subclinical lung disease underwent bronchoalveolar lavage. Eleven patients with known interstitial lung disease and rheumatoid arthritis were identified from the records of bronchoalveolar lavage performed by us from 1984 to 1988 . These patients and their hospital case notes were reviewed (notes only if the patient had died). Identical information to that of the screened patients was obtained plus details of the course and therapy of their pulmonary disease. Four healthy volunteers and 11 hospital inpatients who had no lung disease were included as a control group. They had normal results in their pulmonary function tests, performed before lavage.

The study was approved by the ethics committee of St Vincent's Hospital. Patients gave oral consent to the initial tests and written consent to bronchoscopy and bronchoalveolar lavage.

\section{BRONCHOALVEOLAR LAVAGE}

Bronchoalveolar lavage was performed during fibreoptic bronchoscopy under local anaesthesia. The lavage was performed in a segmental or subsegmental right middle lobe bronchus. Premedication with atropine $(0.6 \mathrm{mg})$ and pethidine $(50 \mathrm{mg})$ was routine and further sedation with $5-10 \mathrm{mg}$ intravenous diazepam was given as required. Before lavage the bronchus was anaesthetised with $2 \mathrm{ml}$ of $1 \%$ lignocaine hydrochloride. The bronchoscope was wedged in a subsegmental bronchus and $180 \mathrm{ml}$ of $0.9 \%$ saline (at $37^{\circ} \mathrm{C}$ ) was infused in three $60 \mathrm{ml}$ aliquots with gentle suction after each infusion. The volume of the aspirated fluid was recorded and the fluid strained through sterile surgical gauze to remove mucus. The fluid was then centrifuged at $400 \mathrm{~g}$ for 10 minutes and the supernatant stored at $-20^{\circ} \mathrm{C}$ for subsequent analysis.

\section{CELLULAR ANALYSIS}

The recovered cells were washed twice in Hanks' balanced salt solution and resuspended in RPMI 1640 to a concentration of $2 \times 10^{6}$ cells $/ \mathrm{ml}$. Total $\mathrm{T}$ lymphocytes and $\mathrm{T}$ lympho- cyte subsets were analysed by fluorescent microscopy, murine monoclonal antibodies being used..$^{14}$ Differential counts of lymphocytes, macrophages, and neutrophils were performed on Wright-Giemsa stained cell smears by a second observer. Where there was a difference between the methods of over $10 \%$ for the percentage of lymphocytes an esterase stained smear was used to distinguish small macrophages from large lymphocytes.

\section{ANALYSIS OF LAVAGE FLUID}

Before analysis fluid was centrifuged at $1000 \mathrm{~g}$ for 15 minutes, phenylmethylsulphonylfluoride (PMSF, final concentration $0.1 \mathrm{mmol} / \mathrm{l}$ ) was added to prevent protease digestion, and the solution was concentrated 20 fold by ultrafiltration in CF25 Centriflo membrane cones (Amicon Corporation, Danvers, USA). Average protein recovery after concentration was $73 \cdot 2 \%(n=20$, coefficient of variation $=18 \%$ ). Fluid was analysed for collagenase, procollagen peptide, fibronectin, protein, and urea. ${ }^{149}$ As no satisfactory reference component for normalising lavage fluid proteins is available, ${ }^{20}$ concentrations of collagenase, procollagen peptide, and fibronectin were calculated per $\mathrm{ml}$ of lavage fluid, per $\mathrm{mg}$ of bronchoalveolar lavage protein, and per $\mu \mathrm{g}$ of bronchoalveolar lavage urea. ${ }^{14}$ Only where differences between groups were statistically significant for all three calculations were they accepted as being truly significant.

\section{SUBSTRATE SPECIFICITY OF BRONCHOALVEOLAR \\ LAVAGE COLLAGENASE}

For investigating the substrate specificity of lavage fluid collagenase, samples containing collagenase were pooled and assessed for their ability to digest radiolabelled type I (specific activity $3 \times 10^{5} \mathrm{cpm}$ ) and type III (specific activity $8.4 \times 10^{5} \mathrm{cpm}$ ) collagen. Assay of type III collagen digestion was the same as for type I collagen $^{14}$ except that all incubations were carried out for 24 hours. In addition, digestion of both types of collagen was performed at $25^{\circ} \mathrm{C}$ and digestion products were analysed by SDSpolyacrylamide gel electrophoresis.

\section{STATISTICAL ANALYSES}

Statistical analyses were performed with Statgraphics (Statistical Graphics Corporation, Rockville, Maryland, USA), a statistical software package for use with IBM personal computers. Comparisons were made by nonparametric statistical analysis (Wilcoxon rank test). Yates's corrected $\chi^{2}$ test was used for comparison of proportions. ${ }^{21}$ Data on lavage fluid are expressed as medians and absolute ranges.

\section{Results}

Of the 93 patients screened for lung disease, 14 had subclinical interstitial lung disease. Their clinical features are shown in table 1 . Three of the 14 patients had abnormal chest radiographs and restrictive impairment, one had restrictive impairment alone, and 10 had an abnormal chest radiograph without evidence of pulmonary restriction. The radiograph infiltrate was 
Table 1 Clinical features of patients with rheumatoid arthritis $(R A)$ found to have subclinical pulmonary disease at screening

\begin{tabular}{|c|c|c|c|c|c|c|c|c|c|c|c|}
\hline $\begin{array}{l}\text { Patient } \\
\text { No }\end{array}$ & $\begin{array}{l}\text { Age } \\
(y), \\
\text { sex }\end{array}$ & $\begin{array}{l}\text { Duration } \\
(y) \\
\text { of } R A\end{array}$ & $R F$ & $\begin{array}{l}\text { ARA } \\
\text { class }\end{array}$ & $\begin{array}{l}\text { Treatment } \\
\text { (not NSAI) }\end{array}$ & $\begin{array}{l}\text { Smoking } \\
\text { history }\end{array}$ & $\begin{array}{l}\text { Dyspnoea } \\
\text { (NYHA) }\end{array}$ & Signs & $\begin{array}{l}\text { Chest } \\
\text { radiograph } \\
\text { score }^{\star}\end{array}$ & $\begin{array}{l}F V C \\
\text { (\% pred) }\end{array}$ & $\begin{array}{l}\text { Overall } \\
B A L \text { result }\end{array}$ \\
\hline 1 & $38 \mathrm{~F}$ & 9 & - & 3 & $\mathrm{Au}$ & $\mathrm{Cr}$ & 1 & - & $S, 2 / 1$ & 107 & Normal \\
\hline 2 & $55 \mathrm{~F}$ & 32 & - & 2 & $\mathrm{PC}, \mathrm{Au}, \mathrm{ST}$ & Ex & 1 & - & $\mathrm{T}, 1 / 2$ & 36 & Increased $\% \mathrm{~T}$ cells \\
\hline 3 & $52 \mathrm{M}$ & 18 & + & 2 & $\mathrm{Au}$ & Ex & 2 & cr & $\mathrm{T}, 1 / 2$ & 90 & Normal \\
\hline 4 & $58 \mathrm{M}$ & 2 & + & 2 & - & Ex & 1 & - & $\mathrm{T}, 1 / 2$ & 83 & Not available \\
\hline 5 & $53 \mathrm{M}$ & 11 & + & 1 & $\mathrm{Au}, \mathrm{PC}, \mathrm{ST}$ & $\mathrm{Cr}$ & 1 & - & $\mathrm{T}, \mathbf{1} / \mathbf{1}$ & 98 & $\begin{array}{l}\text { Increased } \\
\text { collagenase }\end{array}$ \\
\hline 6 & $54 \mathrm{M}$ & 27 & + & 3 & $\mathrm{Au}, \mathrm{ST}, \mathrm{MX}$ & $\mathrm{Cr}$ & 1 & Pleural rub, cl & $\mathrm{Y}, 2 / 2$ & 83 & Not available \\
\hline 7 & $52 \mathrm{~F}$ & 11 & - & 2 & & Never & 1 & & $\mathrm{~T}, 1 / 2$ & 71 & $\begin{array}{l}\text { Increased } \\
\text { collagenase }\end{array}$ \\
\hline 8 & $62 M$ & 6 & + & 3 & ST & Ex & 3 & $\mathrm{cl}, \mathrm{cr}$ & $\mathrm{U}, 2 / 2$ & 35 & Not available \\
\hline 9 & $54 \mathrm{M}$ & 18 & + & 2 & $\mathrm{Au}$ & Ex & 2 & - & $\mathrm{T}, 2 / 2$ & 84 & $\begin{array}{l}\text { Increased \% } \\
\text { neutrophils }\end{array}$ \\
\hline 10 & $59 \mathrm{~F}$ & 1 & + & 2 & $\mathrm{Au}$ & $\mathrm{Cr}$ & 1 & - & $Y, 2 / 1$ & 103 & Not available \\
\hline 11 & $27 \mathrm{~F}$ & 4 & + & 2 & $\mathrm{Au}, \mathrm{PC}, \mathrm{ST}$ & $\mathrm{Cr}$ & 1 & - & $0 / 0$ & 61 & Normal \\
\hline 12 & $60 M$ & 12 & + & 3 & $\mathrm{Au}, \mathrm{PC}, \mathrm{ST}$ & $\mathrm{Cr}$ & 1 & - & $\mathrm{T}, 1 / 1$ & 93 & Normal \\
\hline 13 & $38 \mathrm{~F}$ & 5 & + & 2 & $\mathrm{Au}$ & $\mathrm{Cr}$ & 1 & - & $\mathrm{Y}, 2 / 1$ & 100 & Normal \\
\hline \multirow{2}{*}{$\begin{array}{l}\text { Mean } \\
\text { (SD) }\end{array}$} & $57 \mathrm{~F}$ & 3 & + & 2 & $\mathrm{Au}, \mathrm{ST}$ & $\mathrm{Cr}$ & 1 & - & $\mathrm{Y}, 2 / 1$ & 86 & Normal \\
\hline & $51(10)$ & \multicolumn{2}{|l|}{$11(9)$} & \multicolumn{2}{|c|}{$2 \cdot 2(0 \cdot 6)$} & & \multicolumn{2}{|l|}{$1 \cdot 3(0 \cdot 6)$} & & \multicolumn{2}{|l|}{$81(23)$} \\
\hline
\end{tabular}

${ }^{\star} I L O .^{17}$

RF-rheumatoid factor; ARA-American Rheumatology Association; NSAI-non-steroidal anti-inflammatory drug; Au-gold; PC-penicillamine; ST_-steroid; MX-methotrexate; Cr-current smoker; Ex-previous smoker ( $>6$ months before); NYHA - New York Heart Association; cl-clubbing; cr-crackles; BALbronchoalveolar lavage.

usually bilateral, situated in the middle and lower zones, but varied in type.

Comparison of the clinical histories of patients with ( $n=14)$ and without $(n=79)$ subclinical pulmonary disease indicated that the only significant difference between the two groups was a much higher frequency of current or past cigarette smoking in patients with pulmonary disease $(p<0.05$; table 2$)$. The clinical features of the 11 patients with established interstitial lung disease are shown in table 3. These patients had more symptoms, higher profusion scores on the chest radiograph, and worse pulmonary function than patients identified from screening. The proportion of current or past smokers among patients with established interstitial lung disease was similar to that in the screened group. The prognosis in the group with established disease was poor: five patients had died since initial bronchoalveolar lavage and three of the deaths were

Table 2 Comparison of the clinical characteristics of screened patients with rheumatoid arthritis with and without subclinical lung disease

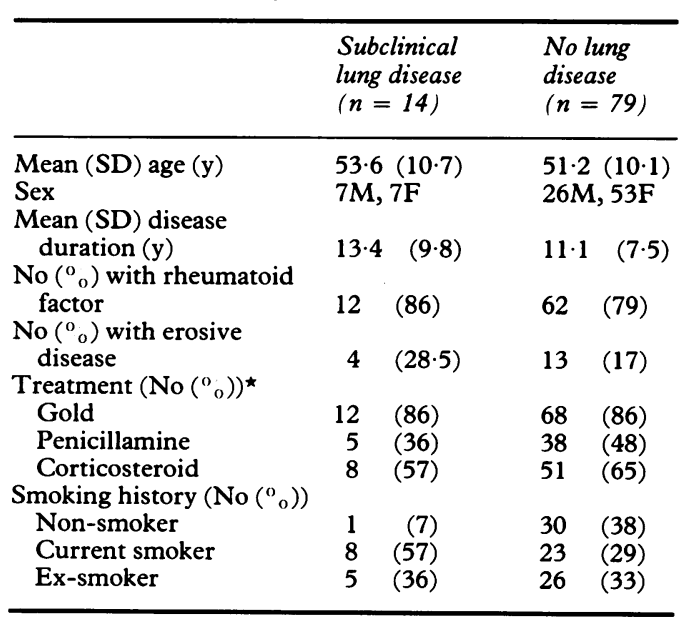

*Current or previous treatment. related to interstitial lung disease or its treatment. Corticosteroid alone $(n=4)$ or corticosteroid plus azothiaprine $(n=3)$ had not produced a sustained improvement in any patient. The addition of cyclophosphamide in one patient and methotrexate in another was associated with some improvement in pulmonary symptoms (table 3 ).

Bronchoalveolar lavage results from both groups of patients were compared with those from the 15 control subjects. Cellular analyses (table 4) showed no differences between the control and the rheumatoid arthritis group in the proportion of $\mathrm{T}$ lymphocytes recovered or the $T$ cell phenotype. The proportion of neutrophils recovered was significantly greater in the patients with rheumatoid arthritis and established interstitial lung disease than in the control subjects. Only two patients with subclinical disease had abnormal cell counts (table 1). One (patient 9) had a raised neutrophil count ( $43 \%$ of inflammatory cells); the other (patient 2) had an increased proportion of $\mathrm{T}$ lymphocytes ( $52 \%$ of inflammatory cells).

The volume of bronchoalveolar lavage fluid recovered (table 4) was smaller in both rheumatoid arthritis groups. Patients with rheumatoid arthritis also had greater protein concentrations than control subjects; urea concentrations were similar in the three groups. Patients with established interstitial lung disease had a greater procollagen peptide concentration $(p<0.02)$ and collagenase activity ( $p<$ 0.01 ) in the lavage fluid than either the control group or those with subclinical disease (figure). These differences remained when results were expressed per mg of protein or per $\mu \mathrm{g}$ of urea in the lavage fluid. In patients with established interstitial lung disease collagenase activity and procollagen peptide concentration were positively correlated $(r=0.64, p<0.05$, Spearman rank test). Only one patient with established interstitial lung disease (patient 9, table 3) had no detectable levels of either lavage fluid 
Table 3 Clinical features of patients with rheumatoid arthritis (RA) and established interstitial lung disease (ILD)

\begin{tabular}{|c|c|c|c|c|c|c|c|c|c|}
\hline Case No & $\begin{array}{l}\operatorname{Age}^{\star}(y), \\
\operatorname{sex}\end{array}$ & $\begin{array}{l}\text { Duration (y) } \\
\text { of } R A^{\star}\end{array}$ & $R F$ & $\begin{array}{l}\text { ARA } \\
\text { class }\end{array}$ & $\begin{array}{l}\text { Treatment } \\
(\text { not } N S A I)\end{array}$ & $\begin{array}{l}\text { Smoking } \\
\text { history }\end{array}$ & $\begin{array}{l}\text { Dyspnoea } \dagger \\
(N Y H A)\end{array}$ & Signs† & $\begin{array}{l}\text { Chest } \\
\text { radiograph } \\
\text { score } \dagger\end{array}$ \\
\hline 1 & $70 \mathrm{M}$ & 20 & + & 2 & - & Ex & 3 & $\mathrm{cl}, \mathrm{cr}$ & $\mathrm{U}, 3 / 2$ \\
\hline 2 & $62 M$ & 1 & + & 2 & $\mathrm{Au}$ & Ex & 2 & cr & $\mathrm{T}, 2 / 2$ \\
\hline 3 & $59 \mathrm{M}$ & 9 & + & 2 & - & $\mathrm{Cr}$ & 2 & $\mathrm{cl}, \mathrm{cr}$ & $\mathbf{N} / \mathbf{A}$ \\
\hline 4 & $66 M$ & Coincident & + & 2 & - & Ex & 3 & $\mathrm{cl}, \mathrm{cr}$ & N/A \\
\hline $\begin{array}{l}5 \\
6\end{array}$ & $\begin{array}{ll}61 & M \\
58 & M\end{array}$ & $\begin{array}{l}2 \\
8\end{array}$ & $\overline{+}$ & $\begin{array}{l}3 \\
2\end{array}$ & $\begin{array}{l}\mathrm{Au} \\
\mathrm{Au}\end{array}$ & $\begin{array}{l}\mathrm{Ex} \\
\mathrm{Cr}\end{array}$ & $\begin{array}{l}3 \\
2\end{array}$ & $\begin{array}{l}\mathrm{cr} \\
\mathrm{cl}, \mathrm{cr}\end{array}$ & $\begin{array}{l}\mathrm{T}, 2 / 3 \\
\mathrm{~S} / \mathrm{T}, 2 / 2\end{array}$ \\
\hline 7 & $58 \mathrm{M}$ & 9 & + & 2 & $\mathrm{Au}$ & Ex & 3 & $\mathrm{cr}$ & $\mathrm{U}, 3 / 2$ \\
\hline 8 & $51 \mathrm{M}$ & 6 & + & 2 & DXT to feet & $\mathrm{cr}$ & 3 & $\mathrm{cr}$ & $\mathrm{U}, 2 / 2$ \\
\hline $\begin{array}{r}9 \\
10 \\
11\end{array}$ & $\begin{array}{ll}56 & F \\
51 & F \\
54 & F\end{array}$ & $\begin{array}{l}14 \\
10 \\
7 / 12\end{array}$ & $\begin{array}{l}+ \\
+ \\
+\end{array}$ & $\begin{array}{l}3 \\
3 \\
1\end{array}$ & $\begin{array}{l}\mathrm{Au}, \mathrm{PC}, \mathrm{ST} \\
\mathrm{Au}, \mathrm{PC}, \mathrm{ST}, \mathrm{DXT} \\
-\end{array}$ & $\begin{array}{l}\text { cr } \\
\text { Never } \\
\text { Ex }\end{array}$ & $\begin{array}{l}2 \\
3 \\
2\end{array}$ & $\begin{array}{l}\text { Pleural rub } \\
\mathrm{cl}, \mathrm{cr} \\
\mathrm{cr}\end{array}$ & $\begin{array}{l}\mathrm{T}, 1 / 2 \\
\mathrm{~T}, 2 / 1 \\
\mathrm{~T}, 2 / 2\end{array}$ \\
\hline Mean (SD) & $59(9)$ & $7(6)$ & & $2 \cdot 2(0 \cdot 6)$ & & & $2.5(0.5)$ & & \\
\hline
\end{tabular}

^At the time of diagnosis of interstitial lung disease.

tAt the time of bronchoalveolar lavage.

N/A - radiograph not available for review; DXT—radiotherapy; AZ—azothiaprine; CP-cyclophosphamide. Other abbreviations as in table 1.

collagenase or procollagen peptide. This patient had the least lung infiltration in this group, and was the only patient to remain stable with corticosteroids alone. This patient's main pulmonary problem was pleurisy, which contributed to the low FVC\% observed.

Lavage fluid concentrations of fibronectin were similar in control subjects and patients. Median lavage procollagen peptide concentrations were similar in the control subjects and the patients with subclinical interstitial lung disease. Collagenase was not detected in bronchoalveolar lavage fluid from control subjects, but was found in the lavage fluid from two patients with subclinical interstitial lung disease (Nos 5 and 7; table 1 and figure). The four patients with subclinical lung disease and abnormal lavage fluid profiles did not differ from other patients in this group with respect to the duration, severity, or treatment of their rheumatoid arthritis or their smoking history.

The rate of degradation of type I collagen by a pooled sample of lavage fluid collagenase was $250 \mu \mathrm{g}$ collagen degraded per $\mathrm{ml}$ of the sample.
No degradation of type III collagen occurred after incubation for 24 hours. This specificity for type I collagen was confirmed by SDSPAGE analysis of digestion products, which showed collagen fragments from type I but not from type III collagen. The failure of lavage fluid collagenase to cleave type III collagen strongly suggests that the enzyme is of neutrophil origin. ${ }^{22}$

\section{Discussion}

Screening of 93 patients with established rheumatoid arthritis identified 14 patients with subclinical lung disease. An association between the presence of subclinical interstitial disease and a history of cigarette smoking was observed. In addition, 10 of the 11 patients with rheumatoid arthritis and established interstitial lung disease were current smokers or ex-smokers. Previous studies have also shown that current smokers with rheumatoid arthritis have a higher incidence of pulmonary

Table 4 Analysis of bronchoalveolar lavage samples from patients with rheumatoid arthritis $(R A)$ and control subjects (medians (absolute ranges))

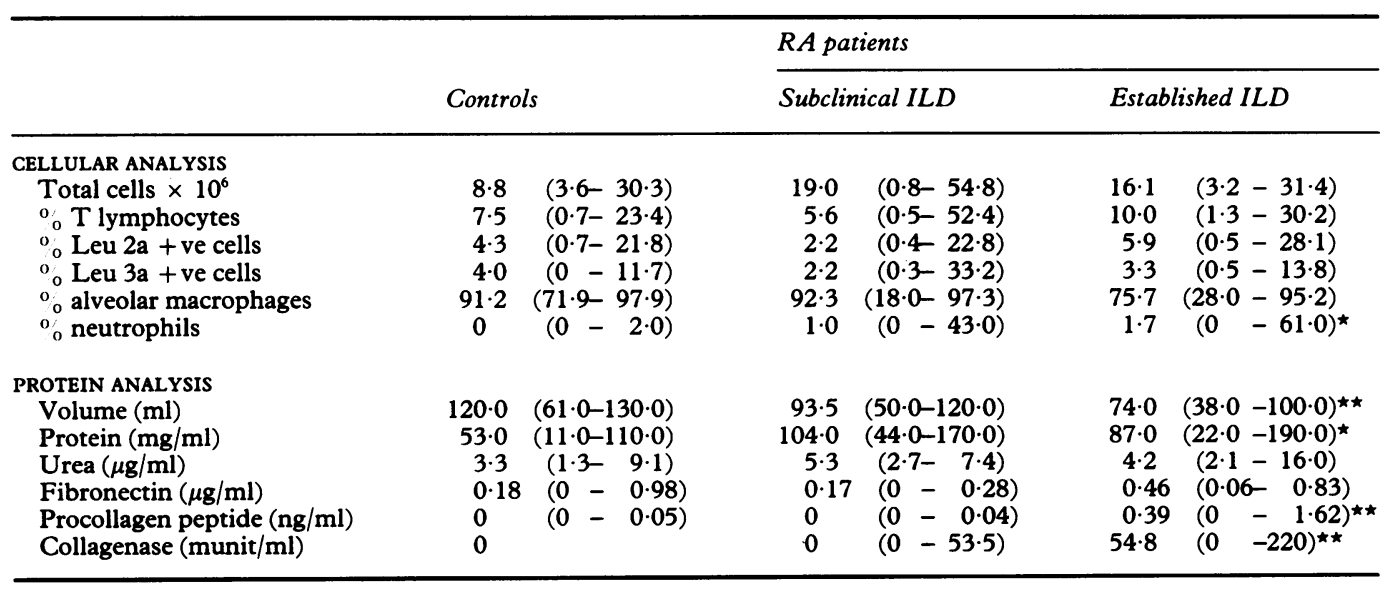

${ }^{\star} \mathrm{p}<0.05,{ }^{\star \star} \mathrm{p}<0.01$ compared with controls (Wilcoxon rank sum test). 


\begin{tabular}{|c|c|c|c|}
\hline $\begin{array}{l}F V C \dagger \\
(\% \text { pred })\end{array}$ & $\begin{array}{l}\text { Treatment of } \\
I L D\end{array}$ & $\begin{array}{l}\text { Duration of } \\
\text { follow up }\end{array}$ & Outcome \\
\hline 46 & ST & $7 \mathrm{~m}$ & $\begin{array}{l}\text { Initial improvement in lung function tests; } \\
\text { died from pneumonia }\end{array}$ \\
\hline 75 & ST, AZ, MX & $2 \mathrm{y}$ & $\begin{array}{l}\text { Responded to ST/MX, FVC up to } 85 \% \\
\text { predicted }\end{array}$ \\
\hline 76 & ST, AZ & $4 y$ & $\begin{array}{l}\text { Progressive deterioration in lung function } \\
\text { tests; died of myocardial infarct }\end{array}$ \\
\hline $1 \cdot 4 / 3 \cdot 8$ & ST & $2 \mathrm{y}$ & $\begin{array}{l}\text { Initial improvement in lung function tests; } \\
\text { subsequent deterioration }\end{array}$ \\
\hline 36 & ST & $4 \mathrm{~m}$ & Died from gastric bleed and cardiac failure \\
\hline 80 & Nil & $1 \mathrm{y}$ & $\begin{array}{l}\text { Bronchial adenocarcinoma found } \\
\text { concurrently with ILD; died from } \\
\text { metastatic disease }\end{array}$ \\
\hline 84 & ST, AZ & $8 \mathrm{y}$ & $\begin{array}{l}\text { Progressive deterioration; most recent } \\
\text { FVC } 36 \%\end{array}$ \\
\hline 59 & ST, AZ & $8 \mathrm{~m}$ & $\begin{array}{l}\text { Presented with pneumothorax; progressive } \\
\text { deterioration and died of pneumonia }\end{array}$ \\
\hline 42 & ST & $6 \mathrm{~m}$ & Unchanged \\
\hline 50 & ST, CP & $2 y$ & Unresponsive to ST, CP added \\
\hline 50 & ST, CP & $2 y$ & $\begin{array}{l}\text { VC improved to } 86 \% \text { after } 6 \text { months } \mathrm{ST}+ \\
\mathrm{CP}\end{array}$ \\
\hline $58(18)$ & & $2 \cdot 1(2 \cdot 2) y$ & \\
\hline
\end{tabular}

Bronchoalveolar lavage ( $B A L)$ fluid collagenase (A) and type III procollagen peptide $(B)$ in control subjects and patients with rheumatoid arthritis and mild and established interstitial lung disease. study the pathogenesis of interstitial lung dis- abnormalities than control subjects. ${ }^{6}$ No association was observed between the presence of interstitial lung disease and the duration, severity, or treatment of the rheumatoid arthritis, confirming earlier reports. ${ }^{34}$

Bronchoalveolar lavage is widely used to

BAL

collagenase

$(\mathrm{mU} / \mathrm{ml})$

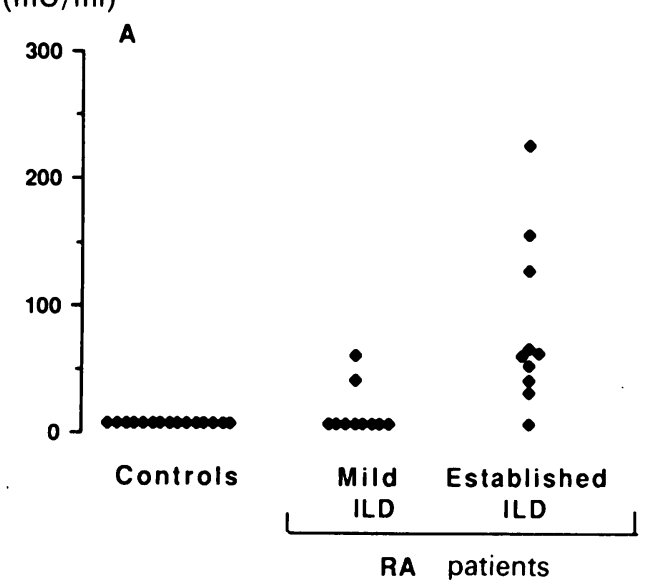

BAL

procollagen

peptide

$(\mathrm{ng} / \mathrm{ml})$

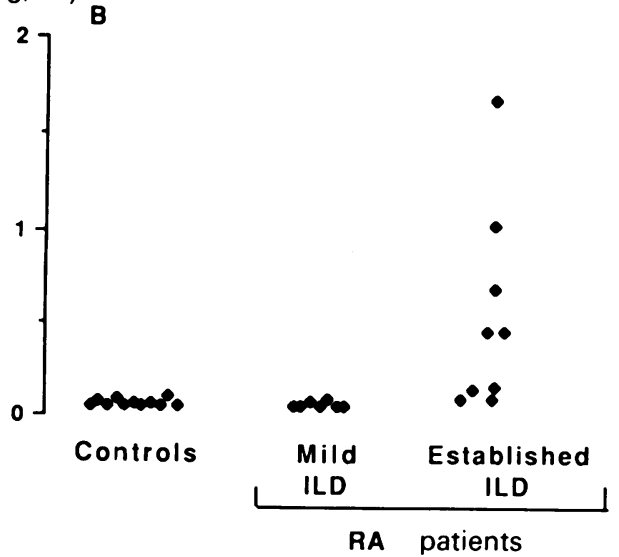

eases and alterations in lavage fluid constituents may be useful in predicting disease progression and response to treatment. ${ }^{23}$ In interstitial lung disease associated with rheumatoid arthritis only a proportion of patients who display pulmonary interstitial abnormalities develop severe fibrotic disease, and for those who do the prognosis and response to treatment are poor. Thus studies on rheumatoid arthritis associated interstitial lung disease have sought to identify changes in lavage fluid constituents that may presage aggressive pulmonary disease. The alveolitis associated with rheumatoid arthritis is clinically and morphologically similar to cryptogenic fibrosing alveolitis, a disease that has been more extensively studied than lung disease associated with rheumatoid arthritis. Lavage fluid changes implicated in the pathonesis of cryptogenic fibrosing alveolitis include increased neutrophil, eosinophil, collagenase, procollagen peptide, and fibronectin levels. $^{7813-15}$ Increased neutrophils and collagenase have also been found in lavage fluid from patients with rheumatoid arthritis and symptomatic interstitial lung disease $\mathrm{e}^{910}$ and the present study confirmed this finding. The substrate specificity of the lavage collagenase suggests that the neutrophil is the major source of this enzyme. Using similar techniques, Weiland et al ${ }^{10}$ came to the same conclusion in their study of patients with rheumatoid arthritis. Thus bronchoalveolar lavage collagenase may be a further marker of activated neutrophils in the lower respiratory tract in patients with rheumatoid arthritis. ${ }^{24}$

Increased type III procollagen peptide in the lavage fluid, produced during type III collagen deposition in the interstitial matrix, was also observed in our patients with established interstitial lung disease. A similar increase in type III procollagen peptide has been observed in lavage fluid in patients with various interstitial lung disorders. ${ }^{1525}$ The significance of increased type III procollagen peptide in the development of fibrosing disease is not clear, however, as end stage fibrosis is associated with the increased deposition of type I rather than type III collagen. Bateman et al, ${ }^{26}$ however, in a study of lung biopsy samples from patients with cryptogenic fibrosing alveolitis, found that increased deposition of type III collagen was associated with active fibrogenesis in this disease.

Clinical monitoring of patients with established interstitial lung disease showed a poor response to corticosteroids. Five patients in this group have subsequently died, three as a result of pulmonary disease or its treatment. A similarly poor response to corticosteroids has been noted in cryptogenic fibrosing alveolitis, particularly in patients with increased lavage fluid neutrophils or eosinophils. ${ }^{78}$ Pulmonary symptoms improved in one patient when cyclophosphamide was added to the treatment, as has been seen occasionally in some patients with cryptogenic fibrosing alveolitis who fail to respond to corticosteroids. ${ }^{27}$

Four patients identified as having subclinical interstitial lung disease were found to have 
abnormal bronchoalveolar lavage fluid profiles-one had an increased lymphocyte count, one an increased neutrophil count, and two increased collagenase in the lavage fluid. Garcia et $a l^{9}$ observed increases in lavage fluid lymphocytes in patients with rheumatoid arthritis who had no clinical evidence of pulmonary disease, and so did Tishler et al ${ }^{11}$ in four patients with rheumatoid arthritis and radiographic signs of disease. The meaning of the increased lavage fluid lymphocytes in patients with rheumatoid arthritis is not, however, clear. Wallaert et al, ${ }^{12}$ in a study of 61 patients with various collagen vascular disorders but with no pulmonary disease (including four patients with rheumatoid arthritis), found that patients with increased lavage fluid lymphocytes showed no functional deterioration over 12 months. These investigators concluded that "the presence of a lymphocyte alveolitis does not lead to a clinically significant pulmonary interstitial process per se" in these disorders. Increase in lavage fluid lymphocytes in cryptogenic fibrosing alveolitis patients is associated with a good prognosis and responsiveness to corticosteroids. ${ }^{78}$

In contrast, an increase in lavage fluid neutrophils in patients with or without clinical signs of pulmonary disease is associated with a poor prognosis and lack of responsiveness to treatment. ${ }^{78122728}$ Although only one patient with subclinical interstitial lung disease had a raised neutrophil count in the lavage fluid, a further two patients had increased lavage fluid collagenase, which appears to be of neutrophil origin and may reflect the presence of activated neutrophils in the lower respiratory tract. Thus three of our patients with rheumatoid arthritis and subclinical lung disease had markers that are found in the lavage fluid of patients with rheumatoid arthritis and established pulmonary disease and are associated with a poor prognosis in cryptogenic fibrosing alveolitis. As only a small proportion of patients with rheumatoid arthritis and subclinical lung disease develop chronic fibrosing interstitial lung disease the results of this study suggest that bronchoalveolar lavage in these patients may help to identify those who require careful monitoring in the hope that early treatment may prevent the development of severe interstitial disease.

1 Hunninghake GW, Fauci AS. State of the art: Pulmonary involvement in the collagen vascular diseases. Am Rev involvement in the collagen
Respir Dis 1979;119:471-503.

2 Keogh BA, Crystal RG. Chronic interstitial lung disease. In: Simmons DH, ed. Current pulmonology. Chichester: Wiley, 1981:237-340.

3 Frank T, Weg JG, Harkleroad LE, Fitch RF. Pulmonary dysfunction in rheumatoid disease. Chest 1973;63:27-33. Popper MS, Bogdenoff ML, Hughes RL. Interstitia rheumatoid lung disease. Chest 1972;63:243-9.

5 Hakala M, Ruuska P, Hameenkorpi R, Tiilikainen A, Ilonen $J$, Makitalo $R$. Diffuse interstitial lung disease in Rheumatoid Arthritis. Scand J Rheumatol 1986;15: 368-76.

6 Hyland RH, Gordon RA, Broder I. A systematic controlled study of pulmonary abnormalities in Rheumatoid arthritis. J Rheumatol 1983;10:395-406.

7 Rudd RM, Haslam PL, Turner-Warwick M. Cryptogenic fibrosing alveolitis: relationships of pulmonary physiology and bronchoalveolar lavage to response to treatment and prognosis. Am Rev Respir Dis 1981;124:1-8.

8 Peterson MW, Monick M, Hunninghake GW. Prognostic role of eosinophils in pulmonary fibrosis. Chest 1987;92: 51-6.

9 Garcia JGN, Parhami N, Killam D, Garcia PL, Keogh BA. Bronchoalveolar lavage fluid evaluation in rheumatoid arthritis. Am Rev Respir Dis 1986;133:450-4.

10 Weiland JE, Garcia JGN, Davis WB, Gadek JE. Neutrophil collagenase in rheumatoid interstitial lung disease. $J A p p l$ Physiol 1987;62:628-33.

11 Tishler M, Grief J, Fireman E, Yanow M, Topilsky M. Bronchoalveolar lavage- a sensitive tool for early diagnosis of pulmonary involvement in rheumatoid arthritis. $J$ Rheumatol 1986;13:547-50.

12 Wallaert B, Hatron PY, Grosbois JM, Tonnel AB, Devulder $B$, Voisin C. Subclinical pulmonary involvement in collagen vascular diseases assessed by bronchoalveolar collagen vascular diseases assessed by bronchoalveolar lavage. Relationship between alveolitis and subsequent
changes in lung function. Am Rev Respir Dis 1986;133: changes

13 Gadek JE, Kelman JA, Fells G, et al. Collagenase in the lower respiratory tract of patients with idiopathic pulmonary fibrosis. N Engl J Med 1979;301:737-42.

14 O'Connor C, Odlum C, van Breda A, Power C, FitzGerald $\mathrm{MX}$. Collagenase and fibronectin in bronchoalveolar lavage fluid in patients with sarcoidosis. Thorax 1988;43: 393-400.

15 Cantin AM, Boileau R, Begin R. Increased procollagen III amino terminal peptide-related antigens and fibroblast growth signals in the lungs of patients with idiopathic growth signals in the lungs of patients with idiopathic
pulmonary fibrosis. Am Rev Respir Dis 1988;137:572-8.

16 Decker JL. Primer on the rheumatic diseases. JAMA 1964; 190:741-51.

17 International Labour Office. Guidelines for the use of ILO international classification of radiographs of pneumoconiosis. Geneva: ILO, 1983.

8 Cotes JE. Lung function: assessment and application in medicine. Oxford: Blackwell, 1979:329-87.

19 O'Connor C, Ward K, van Breda A, McIlgorm A, FitzGerald MX. Type III procollagen peptide in bronchoalveolar lavage fluid: poor indicator of course and pronchoalveolar lavage fluid: poor indicator of

20 Reynolds HY. Bronchoalveolar lavage. Am Rev Respir Dis 1987;135:250-63.

21 Snedecor GW, Cochran WG. Statistical methods, 6th ed. Iowa State University Press, 1967.

22 Horwitz AL, Hance AJ, Crystal RG. Granulocyte collagenase: selective digestion of type I relative to type III collagen. Proc Natl Acad Sci USA 1977;74:897-901.

23 Crystal RG, Gadek JE, Ferrens VJ, Fulmer JD, Line BR, Hunninghake GW. Interstitial lung disease: current concepts of pathogenesis, staging and therapy. Am J Med 1981;70:542-68.

24 Garcia JGN, James HL, Zinkgraf S, Perlman MB, Keogh $B A$. Lower respiratory tract abnormalities in rheumatoid interstitial lung disease. Potential role of neutrophils in interstitial lung disease. Potential role of neutr.

lung injury. Am Rev Respir Dis 1987;136:811-7.
25 Low RB, Cutroneo KR, Davis GS, Granala MS. Lavage type III procollagen $N$-terminal peptides in human pulmonary fibrosis and sarcoidosis. Lab Invest 1983;48. 755-9.

26 Bateman ED, Turner-Warwick M, Haslam P, AdelmanGrill BC. Cryptogenic fibrosing alveolitis: prediction of fibrogenic activity from immunohistochemical studies of collagen types in lung biopsy specimens. Thorax 1983;38: 93-101.

27 Turner-Warwick M, Haslam PL. The value of serial bronchoalveolar lavage in assessing the clinical progress of patients with cryptogenic fibrosing alveolitis. Am Rev Respir Dis 1987;135:26-34.

28 Haslam PL, Turton CWG, Heard B, et al. Bronchoalveolar lavage in pulmonary fibrosis: comparison of cells obtained lavage in pulmonary fibrosis: comparison of cells obtained
with lung biopsy and clinical features. Thorax 1980;35: 9-18. 